\title{
LEGITIMACY AND THE USE OF FORCE: BRIDGING THE ANALYTICAL - NORMATIVE DIVIDE
}

Article forthcoming in the Review of International Studies in Vol. 34: 4 (October 2008)

Corneliu Bjola

Assistant Professor

Department of Political Science

McMaster University 


\section{ABSTRACT}

By remaining epistemologically committed to an outdated distinction between facts and values, traditional definitions of legitimacy either divest the concept of an important critical component or fail to properly anchor it in the social reality. As an alternative, the article proposes a constitutive theory of legitimacy that reconciles the epistemological tension via the concepts of fairness and tractability and bridges the theoretical gap via the concept of deliberative legitimacy. By applying it to the issue of the use of force, the article argues that a normatively sound and politically relevant model of legitimacy must take into account both to the manner in which actors' commitment to social norms is crafted and the type of conditions that facilitate or constrain the definition, contestation, and adjudication of what counts as legitimacy in a particular political context. 


\section{Introduction}

What type of considerations should inform the relationship between legitimacy and the use of force in international politics? Why are, for instance, wars in self-defense deemed legitimate but not also interventions for stopping acts of genocide or mass killing? What rules, norms or principles should one consider to make this judgment? In short, how can one know whether a military intervention is legitimate? The question is, of course, hardly new and has been periodically tackled by International Relations (IR) scholars and political theorists from various standpoints. ${ }^{1}$ However, a definitive conclusion on this issue has thus far failed to materialize and for good reasons, which will be examined in more detail further below. The United States' (US) intervention in Iraq in 2003 has forcefully put the subject back on the IR agenda, even prompting journals such as the Review of International Studies or International Politics to produce special issues examining the tensions informing the principles and practices that currently regulate the use of force in international politics. Two research agendas have emerged regarding the issue of legitimacy in general and that of the use of force in particular.

The first approach is analytical and addresses the concept of legitimacy in an explanatory fashion. Its main concern refers to why and how moral or legal norms of legitimacy influence the definition of state interests, foreign policies or the nature of the international order. The second agenda is normative and examines the ethical value of the rules, norms or principles involved in various definitions of legitimacy. It main objective is to compare and evaluate definitions of legitimacy that

${ }^{1}$ Ian Clark, Legitimacy in International Society (Oxford: Oxford University Press, 2005), Thomas M. Franck, The Power of Legitimacy among Nations (New York: Oxford University Press, 1990), Ian Hurd, "Legitimacy and Authority in International Politics," International Organization 53, no. 2 (1999), Ian Johnstone, "Security Council Deliberations: The Power of the Better Argument," European Journal of International Law 14, no. 3 (2003), Jens Steffek, "The Legitimation of International Governance: A Discourse Approach," European Journal of International Relations 9, no. 2 (2003). 
better serve the interests in peace and justice of the international community. Neither approach provides, though, a convincing answer to the question of how to properly discriminate between legitimate vs. illegitimate uses of force. The main reason for that rests with the fact they fail to theoretically connect the social process by which actors' commitment to legal and moral principles of legitimacy is shaped with the normative conditions that facilitate or constrain the definition, contestation, and adjudication of what counts as legitimacy in a particular political context.

A brief overview of a recent and representative set of contributions on the issue of legitimacy serves well to illustrate this point. For Martha Finnemore or Ian Clark, for instance, the task of the IR theorist is purely analytical. The latter is not supposed to judge from the outside what is, or is not, legitimacy, but to understand the inside political processes responsible for the legitimation of international rules. ${ }^{2}$ According to Finnemore, legitimation struggles are basically a "marketplace of multilateral rules” designed to accommodate a new distribution of power among the leading actors. Power is clearly important for shoring up or undermining support for a norm, but it remains unclear the extent to which a power-based relationship can supervene or even abuse a rule-based framework without undermining the normative dimension of the legitimacy of that framework. What Finnemore is thus missing from her analysis is a critical conceptual tool to distinguish between these two forms of cooperation. Unfortunately, she cannot pursue this direction as long as she maintains a sharp distinction between the descriptive and normative meaning of legitimacy.

Clark takes Finnemore's argument a step further as he develops a theoretically insightful and empirically rich analysis of the relationship between procedural and substantive accounts of legitimacy. In so doing, he distinguishes between legitimacy as a property of international society

\footnotetext{
${ }^{2}$ Martha Finnemore, "Fights About Rules: The Role of Efficacy and Power in Changing Multilateralism," Review of International Studies, 31 (2005): 206.
} 
(i.e. shared principles of rightful membership and conduct), and the condition of being legitimate as a property of its actions (i.e., the pursuit of a "tolerable consensus" within the boundaries of existing norms). ${ }^{3}$ This approach allows him to convincingly explain the varying degrees of success the international society has had in legitimating its actions, but less so with respect to what distinguishes legitimate from illegitimate actions. Similar to Finnemore, Clark runs into serious difficulties when trying to explain the international legitimacy of state actions independent of the distribution of power in the system. His suggestion of treating the moral acceptance of the idea of hegemony as a constitutional practice of international society ${ }^{4}$ represents a clear acknowledgement but ultimately ineffective solution to the problem of theorizing legitimacy strictly from an analytical perspective without taking into account the normative aspects underpinning the concept of legitimacy.

Richard Falk acknowledges a greater role for normative considerations of legitimacy than Finnemore and Clark. International law can set limits to states' use of force, but exceptions to these limits are difficult to settle in the absence of an authoritative intergovernmental institution. The solution to this dilemma lies, according to Falk, with redefining the area of competences between legality and legitimacy: "legality clarifies the core obligations relating to force, while legitimacy tries to identify and delimit a zone of exception that takes account of supposedly special circumstances”. ${ }^{5}$ In other words, legitimacy represents a supplement of legality, which can be deployed in two, and only two, sets of circumstances: humanitarian and defensive necessity (i.e., anticipatory self-defence). ${ }^{6}$ The weakness of Falk's argument stems not from his attempt to ground

\footnotetext{
${ }^{3}$ Clark, Legitimacy in International Society: 25-30. This position is also echoed by Reus-Smit for whom international crises of legitimacy are the result of a disconnection between the normative expectations of the international society and actors' social identities and practices: Christian Reus-Smit, "International Crises of Legitimacy," International Politics 44, no. 2-3 (2007).

${ }^{4}$ Clark, Legitimacy in International Society: 242.

${ }^{5}$ Richard Falk, "Legality and Legitimacy: The Quest for Principled Flexibility and Restraint," Review of International Studies, 31 (2005): 35.

6 Ibid.: 50 .
} 
legitimacy into a normative foundation, but from the ambiguities besetting the applicability of his theoretical framework. More specifically, Falk omits to clarify who is entitled to decide whether a particular situation falls under the jurisdiction of the two exceptions (i.e., humanitarian and defensive necessity) and more importantly, how potential abuses of these exceptions could be identified and prevented.

Andrew Hurrell's approach to the issue of legitimacy represents an ambitious attempt to strike a middle-ground position between the analytical and normative perspectives. Hurrell is correct, for instance, when arguing that conceptions of legitimacy should not "open the door to a situation in which it is the strength of a single state or group of states that decides what shall count as law". ${ }^{7} \mathrm{He}$ is also correct when acknowledging that legitimacy ultimately depends "on how far acceptance is the result of internalised belief rather than temporary acquiescence or purchased silence”. ${ }^{8}$ However, what is far less evident in his article is how he squares these two views that is, how he reconciles a moral demand for clear normative distinctions with a practical imperative for resonance with the beliefs and understandings of the actors involved. His conclusion is rather disarming: the character of legitimacy "results from the very difficult combination of recurring political dilemmas and powerful processes of historical change that are unlikely to be quickly, or easily, reversed”. ${ }^{9}$ Other approaches that have tried to combine the two perspectives have also failed to provide a clear understanding of the scope conditions and mechanisms that could accomplish this goal. ${ }^{10}$

The central argument advanced in this article is that current limitations to the study of legitimacy are rooted in epistemology. More specifically, scholars of legitimacy subscribe to either a Weberian or a

${ }^{7}$ Andrew Hurrell, "Legitimacy and the Use of Force: Can the Circle Be Squared?," Review of International Studies, 31 (2005): 29.

${ }^{8}$ Ibid.: 32.

${ }^{9}$ Ibid.

10 Steffek, "The Legitimation of International Governance: A Discourse Approach.", Neta Crawford, Argument and Change in World Politics: Ethics, Decolonization, and Humanitarian Intervention (Cambridge: Cambridge University Press, 2002), 425-35. 
Kantian type of reasoning according to which legitimacy should be studied either in analytical or normative terms that is, as either a description or a prescription of social reality. By remaining committed to an outdated distinction between facts and values, these approaches force the concept of legitimacy to either divest itself of an important critical component or to fail to anchor itself in social reality. As a result, no convincing solution has thus far emerged about how to properly discriminate between legitimate and illegitimate uses of force. I argue instead that an analytically sound and normatively relevant relationship between legitimacy and the use of force must take into account both to the manner in which actors' commitment to social norms is crafted and the type of conditions that facilitate or constrain the definition, contestation, and adjudication of what counts as legitimacy in a particular political context. To this end, the article describes the main epistemological limitations to the study of legitimacy, introduces two important concepts, fairness and tractability, to address them, and outlines ways in which an alternative concept, deliberative legitimacy, could integrate them theoretically. 


\section{Epistemology and the study of the legitimacy}

The importance of the concept of legitimacy in international politics has been relatively wellestablished by now, but the debate in the IR discipline continues to revolve around two related, yet analytically distinct, questions: what exactly is legitimacy and how can the concept be most appropriately studied? A significant part of the confusion that besets the theoretical examination of concept is the result of two epistemological misconceptions. The first stems from the conflation of legitimacy as a second- vs. first-order question. ${ }^{11}$ From the perspective of the former, legitimacy refers to a condition whereby actors voluntarily follow certain decisions. As a first-order question, legitimacy refers to the rules, norms and principles underpinning such decisions. In other words, from an ontological perspective, legitimacy represents, on one hand, a particular form of social action (i.e., how actors relate to each other by means other than coercion or the pursuit of selfinterests), while on the other hand, a specific ethical construct (i.e., a particular combination of moral and legal principles or procedures informing social action). While these two ontological dimensions do generally have a bearing on each other they remain nevertheless analytically distinct: actors' voluntary compliance with a decision to use force may be informed by different combinations of moral and legal principles. In short, the former does not necessarily subsume the latter.

For example, war was considered a legitimate form a social action for the acquisition of a throne in the age of dynasties (1400-1559), protection of religious fate in the age of religions (1559-1648), promoting state power in the age of sovereignty (1648-1789), and for achieving national

\footnotetext{
${ }^{11}$ Second-order questions are concerned with fundamental assumptions of social inquiry such as the relationship between human agency and social structures, while first-order questions are domain-specific and seek to develop concrete propositions about socially and politically relevant issues: Alexander Wendt, Social Theory of International Politics (Cambridge: Cambridge University Press, 1999): 5-6.
} 
independence in the age of nationalism (1789-1917). ${ }^{12}$ More recently, the transformation of warjustifying principles has been driven less by rational calculation of economic and political costs and benefits, as by ethical arguments containing normative beliefs about what was good and right to do to others. For example, the legitimacy of wars for colonial acquisition was undermined by a growing belief in the equality of others and increased respect for the rights of the colonized people. ${ }^{13}$ Similarly, the adoption of the Hague Conventions on the laws of war was made possible by the development of a humanitarian notion that international society had responsibilities for the welfare and well-being of humankind that extended beyond the traditional concerns of individual states. ${ }^{14}$

The second epistemological misconception refers to the causal approach most commonly embraced when theorizing legitimacy. Consequent to their conflation of the two ontological dimensions of legitimacy, most of the studies in the literature focus on identifying the causal factors and conditions that may account for the legitimacy of the use of force in various situations. However, causal theorizing is not amenable to this type of research since the basic premise of causal analysis that is, the existence of a relationship of direct determination between two independently existing variables, ${ }^{15}$ is not applicable to the concept of legitimacy. Unlike causal effects, constitutive factors entail a relationship of identity regarding a particular social condition in the sense that those constitutive effects define what the social condition is. ${ }^{16}$ More specifically, the political dimension of legitimacy (i.e., the substantive and procedural aspects of legal and moral arguments) does not exist independently of the social dimension of legitimacy (i.e., actors' voluntary compliance with

\footnotetext{
${ }^{12}$ Evan Luard, War in International Society: A Study in International Sociology (London: I.B. Tauris, 1986): 133-84.

${ }^{13}$ Crawford, Argument and Change in World Politics: Ethics, Decolonization, and Humanitarian Intervention: 4, 133.

${ }^{14}$ Clark, Legitimacy in International Society: 61.

${ }^{15}$ Gary King, Robert O. Keohane, and Sidney Verba, Designing Social Inquiry: Scientific Inference in Qualitative Research (Princeton, N.J.: Princeton University Press, 1994): 81-2.

${ }^{16}$ Alexander Wendt, "On Constitution and Causation in International Relations," Review of International Studies, 24/5 1998): 106.
} 
these rules and not others). The former constitutes the latter as opposed to "causing” it, that is, it explains how certain rules, norms and principles are put together so that they have the social properties that they do.

The analytical confusion that persists between the constitutive and causal effects of legitimacy is due to the fact that, under certain circumstances, each can create conditions of possibility for the other. On one hand, actors’ recognition of a military intervention as legitimate may cause them to politically support the intervention, to allocate funds and troops for the mission, or to engage in certain diplomatic actions. In other words, the constitutive effect of legitimacy may act as a permissive condition for a causal effect, but other factors need to be present in order for the latter to happen. ${ }^{17}$ By the same token, the causal effect of exogenous factors would serve only as a permissive condition for the constitutive effect of legitimacy. For example, historical memories of the Rwandan tragedy in 1994 could causally inform actors' understanding of the legitimacy of the use of force in future humanitarian crises as long as the persuasive appeal of the analogy would not be undermined by the facts on the ground, by disputes within the interpretative community regarding the relevance of the Rwandan crisis for the case under scrutiny, or by historical reevaluations of the factors responsible for the Rwandan tragedy. Put differently, an exogenous factor cannot really influence actor's understanding of the legitimacy of an action unless it becomes endogenous to the case through interpretation.

In sum, a constitutive theory of legitimacy lacks causal explanations about why actors might decide

\footnotetext{
17 The humanitarian crisis in Rwanda in 1994 convinced the Canadian government of the legitimacy of using force, but lack of adequate resources prevented it from taking strong action to that end. For details, see Romeo Dallaire and Brent Beardsley, Shake Hands with the Devil: The Failure of Humanity in Rwanda (Toronto: Random House Canada, 2003): 207. In other words, the rules, norms and principles implied by a military intervention in response to the humanitarian crisis had a constitutive effect on the Canadian government's recognition of the legitimacy of the action, but that was not enough to produce a causal effect as well.
} 
to support certain decisions as opposed to others, but it provides sound arguments about the properties and structures that make legitimacy possible. These epistemological considerations have important implications for the study of legitimacy of the use of force. More specifically, they indicate how legitimacy should be theorized, what elements a theory of legitimacy should include and why. From a first-order perspective, they call for a theoretical argument that explains what properties and structures make legitimacy possible and how this process takes place. From a secondorder perspective, they call for a theoretical mechanism capable of distinguishing between competing constitutive arrangements of legitimacy. In other words, a constitutive theory of legitimacy involves two levels of critical reasoning: the first is analytical and deals with the substantive principles and procedural norms informing social action (i.e., actors' compliance with a particular decision to use force); the second level is normative and focuses on understanding the validity of the assumptions informing competing conceptions of legitimacy (i.e., why actors voluntarily follow a particular set of substantive principles and procedural norms and not others).

To be sure, the obstacles against articulating a constitutive theory of legitimacy capable of transcending the analytical-normative divide are considerable. Mirroring the distinction advocated by Max Weber long time ago between facts and values, ${ }^{18}$ the IR discipline has largely remained loyal to the view that analytical and normative theories of legitimacy belong to distinct

\footnotetext{
${ }^{18}$ For Weber, science must remain ethically neutral, and not reverse to a pre-modern stage by trying to answer the question of "which of the warring gods should we serve?", since there is no scientific way to refute statements of value: Max Weber, Hans Heinrich Gerth, and C. Wright Mills, From Max Weber: Essays in Sociology (New York,: Oxford University Press, 1946): 153. Facts and values are two different things, and therefore they should not be mixed. Weber's definition of the legitimacy reinforces this distinction very firmly: legitimacy refers only to the belief held by citizens about the character of a political order: Max Weber, Economy and Society; an Outline of Interpretive Sociology (New York,: Bedminster Press, 1968): 903-4. For Weber, legitimacy does not signify an exogenous evaluation of the ethical character of the political system, but an endogenous belief shared by citizens about the system, which can be explored analytically through an interpretative methodology. Critics have claimed though that Weber's positivistic conception of legitimacy is circular and hence unsustainable: on one hand, the legitimacy of a legal order was presumed by Weber to rest on the acceptance of legal authority; on the other hand, he argued that the existence of accepted authority accounts for the existence of legal order. For more details on this point, see Peter M. Blau, "Critical Remarks on Weber's Theory of Authority," American Political Science Review 57, no. 2 (1963), Robert Grafstein, "The Failure of Weber's Conception of Legitimacy: Its Causes and Implications," Journal of Politics 43, no. 2 (1981).
} 
epistemological domains and hence they should be separately pursued. In all fairness, a clear distinction between the two approaches has the merit of providing a good framework for understanding legitimacy within a given system of power relations: where legitimacy originates, how the principles and beliefs that comprise it are maintained and reproduced, why consent is continually renewed, and what social forces are responsible for the erosion of legitimacy. ${ }^{19}$ On the other hand, a strict separation of facts and values tend to reduce legitimacy to a routine submission of authority, ${ }^{20}$ obscures the problem of legitimation crisis of modern political orders, ${ }^{21}$ entails moral relativism, justifies tyranny, and thus leads to theoretical inconsistency. ${ }^{22}$

The epistemological considerations discussed above add further weight to the argument that the separate examination of legitimacy from normative and analytical perspectives as informed by Weber's value-fact distinction is no longer theoretically sustainable. On one hand, an analytical approach focused only on the level of social action risks downgrading the concept of legitimacy to the level of blind compliance. Claiming, for instance, like Henry Kissinger that legitimacy is whatever great powers agree to be, ${ }^{23}$ does not explain why states agree to voluntarily follow certain legal or moral principles and not others. As pointed out by Rescher, if the goal of social inquiry is the rational quest for truth and not for deception, then the validity of actors' consensus is contingent upon reaching this goal: "it is never just consensus we want but the right sort of consensus". ${ }^{24} \mathrm{~A}$ sound theory of legitimacy must thus involve not only a constitutive analysis of how actors develop

\footnotetext{
${ }^{19}$ David Beetham, The Legitimation of Power, Issues in Political Theory (Atlantic Highlands, NJ: Humanities Press International, 1991): 101.

${ }^{20}$ Grafstein, "The Failure of Weber's Conception of Legitimacy: Its Causes and Implications": 456.

${ }^{21}$ Jürgen Habermas, Legitimation Crisis (Boston: Beacon Press, 1975).

22 Jean-Marc Coicaud and David Ames Curtis, Legitimacy and Politics: A Contribution to the Study of Political Right and Political Responsibility (Cambridge: Cambridge University Press, 2002): 89-94.

${ }^{23}$ Henry Kissinger, A World Restored, [Universal library] ed., Grosset's Universal Library, 170 (New York: Grosset \& Dunlap, 1964): 145.

${ }^{24}$ Nicholas Rescher, Pluralism: Against the Demand for Consensus (Oxford: Oxford University Press, 1993): 15-16.
} 
consensus regarding the use of force but also a normative understanding of the basis of that consensus.

On the other hand, a model of legitimacy revolving only around strong normative standards can deprive the concept of its practical value. More specifically, the concept of legitimacy cannot be reduced to an essentialist normative description of substantive principles and procedural rules about actors deciding what and how regarding the use of force. Legitimacy rests on an intersubjective understanding, the meaning of which is only partially fixed by authoritative texts such as legal conventions or moral doctrines. A significant other part is created and fixed through politics, understood as the process of articulation and maximization of actors' political interests through the deliberative construction of social reality. This process is clearly informed by various legal and moral constraints stipulated in foundational texts, but deliberation plays a crucial role since only through an exchange of arguments actors decide what textual interpretations of legitimacy are more valid in a particular situation and why. Therefore, a thorough evaluation of the legitimacy of a military intervention requires a conceptual tool able to account not only for normative provisions of legal and moral texts but also for the political process through which excess of meaning of legitimacy is created through argumentation. 


\section{Seizing the middle-ground: fairness, tractability, and deliberative legitimacy}

Can the analytical-normative gap in the study of legitimacy be really bridged? My answer is yes, but with a caveat. In order to achieve this objective, a sound conception of legitimacy must pay close attention to the process by which actors' commitment to social norms is determined as well as to the substance of the conditions that facilitate or constrain the definition, contestation, and adjudication of what counts as legitimacy in a particular political context. Against the analytical model, one needs to ground the concept of legitimacy in a reasonable moral foundation. Against strong normative prescriptions, one needs to attune these normative standards to the political context in which decisions about the use of force are taken. From a theoretical viewpoint, this transformation can be achieved in two steps. From a second-order perspective, I propose the concepts of fairness and tractability for understanding the moral and practical value of competing constitutive arrangements of legitimacy. From a first-order perspective, I draw on Jürgen Habermas’ theories of communicative action and discourse ethics ${ }^{25}$ to advance the concept of deliberative legitimacy as a constitutive analytical framework.

\section{1. Fairness and legitimacy}

In general terms, the concept of fairness refers both to a principle and a procedure for solving cooperation problems, especially when moral disputes and conflicting rules are involved. In a classical formulation, H.L.A. Hart defined fairness as a "mutuality of restrictions" aimed at precluding free-riding: "when a number of persons conduct any joint enterprise according to rules

\footnotetext{
25 Jürgen Habermas, Justification and Application: Remarks on Discourse Ethics (Cambridge: MIT Press, 1993), Jürgen Habermas, The Theory of Communicative Action, vol. 2, Beacon Paperback (Boston: Beacon Press, 1984).
} 
and thus restrict their liberty, those who have submitted to these restrictions when required have a right to a similar submission from those who have benefited by their submission”.${ }^{26}$ In more direct terms, the distribution of benefits and burdens within a collectivity must be immune to discriminatory practices. This definition has been criticized on two grounds: first, that it is indifferent to the nature of the benefit received and the burden required; second, that "imposes" a benefit upon someone and then extracts payment without asking whether one wanted the benefit in the first place. ${ }^{27}$ In other words, the costs of compliance incurred by certain actors might outweigh the benefits received, a situation that could become even more problematic if the requirement for consent would be eliminated. The overall distribution of the "mutuality of restrictions" would then unduly favor certain participants at the expense of others. The issue of the proportionality of the burdens and the requirement for consent are serious objections to Hart's definition of fairness, but they are nevertheless limited.

Let us consider, for example, that a group of actors accepts sharing proportionally the burdens and benefits of a particular task, but their consent to participating to the joint operation, as well as to distributing the benefits and burdens among themselves is obtained through coercion or intimidation. Could that be described as a fair agreement? After all, all parties submit to the same restrictions, they also agree to distribute proportionally the burdens and benefits of the joint enterprise among themselves, and all of them grant their explicit consent to the undertaking. Yet, the manner in which this agreement is reached suffers of a fundamental flaw: it is based on coercion, not

\footnotetext{
${ }^{26}$ A similar definition was proposed by John Rawls: "The main idea is that when a number of persons engage in a mutually advantageous cooperative venture according to rules, and thus restrict their liberty in ways necessary to yield advantages for all, those who have submitted to these restrictions have a right to a similar acquiescence on the part of those who have benefited from their submission”: John Rawls, A Theory of Justice (Cambridge, Mass.: Belknap Press of Harvard University Press, 1971): 112.

${ }^{27}$ Both points of criticism belong to: Robert Nozick, Anarchy, State, and Utopia (New York: Basic Books, 1974) : 93-4, and are discussed in more detail in Craig L. Carr, On Fairness (Aldershot: Ashgate, 2000): 26-41 and George Klosko, The Principle of Fairness and Political Obligation, New ed., Studies in Social, Political, and Legal Philosophy (Lanham, Md.: Rowman \& Littlefield, 2004): 33-57.
} 
on voluntary and deliberate consent of the subjects involved. A more comprehensive definition of fairness must take this aspect into consideration as well. Fairness should then refer to a mutuality of freely consented restrictions: when a number of persons agree freely, that is, voluntarily and deliberately, to participate and to share proportionally the burdens and benefits of a joint enterprise, those who have submitted to these restrictions have a right to a similar conduct from those who benefited from their submission. This definition highlights several important contributions the concept of fairness can make to theorizing legitimacy.

First, fairness offers an excellent moral anchor for legitimacy. Legitimacy without a moral foundation is blind compliance. Although connected, the two concepts, legitimacy and compliance, cannot be conflated, since significant differences exist between being obligated to do something and being obliged to do something. ${ }^{28}$ The first case refers to the situation when actors comply with a request or a norm because of external constraints, as when someone is forced or intimidated to do something she/he would not otherwise do. The second case refers to the situation when someone follows a norm as a result of internal or subjective constraints, that is, the decision taken is based solely on personal considerations, free of external pressures. The concept of legitimacy can be associated only with the second type of social action, because only in this situation does the subject want to follow a norm, and to fully accept its claims on itself . By subjecting all actors to the same standard of the "mutuality of freely consented restrictions", fairness helps make this crucial distinction between external and subjective conditions of compliance and legitimacy respectively.

Second, fairness provides an effective ontological platform on the basis of which different conceptions of legitimacy can be "legitimately" proposed, challenged, or adjudicated. Whereas the

\footnotetext{
${ }^{28}$ For a more detailed account of the differences between the two types of political obligation, see Klosko, The Principle of Fairness and Political Obligation: 6-12.
} 
previous point speaks to the normative quality of fairness to distinguish between imposed vs. voluntary compliance, this one emphasizes its functional property to facilitate deliberation and argumentation. Any discourse about legitimacy must rest on a set of minimal criteria and necessary conditions that can make possible a discussion on legitimacy in a coherent manner. Put differently, the "rules of the game” must be first agreed upon, in order for actors to be able to "play the game". Otherwise, “the community of 'everyone' will be decimated by dissent before it begins to work” . As a mutuality of freely consented restrictions, fairness serves as an excellent platform for enabling a productive discussion about legitimacy, as long as the conditions for participating to the deliberative process are inclusive and transparent. ${ }^{29}$ On one hand, it is sufficiently general not to restrict the discussion about legitimacy to a few substantive issues that are relevant only to a narrow group of actors. On the other hand, it is sufficiently specific not to render the issue of legitimacy into a vague and futile debate of incommensurable opinions.

Third, fairness is a major catalyst of legitimacy, that is, it can inspire adherence to domestic or international norms, at very low costs, and in an effective manner. The obligatory and voluntary character of certain practices, that is, their legitimacy, cannot be established unless they create "selfextending" emotional attachments that is, emotional reactions that enlarge the "self" of the actors through the inclusion of societal concerns.${ }^{30}$ Obligations based on coercive measures are motivated

\footnotetext{
29 The requirements of transparency and inclusiveness are important for keeping deliberations on the "right” track. Inclusiveness produces meaningful input, whereas transparency makes sure participants are held accountable for their claims James Bohman, "Citizenship and Norms of Publicity: Wide Public Reason in Cosmopolitan Societies," Political Theory 27, no. 2 (1999). Public reasoning and fairness thus reinforce each other, an observation that carries analytical validity not only in national contexts, but also in the global arena. Transparency norms facilitate international fairness by making the practices of global actors and institutions more accountable to interested, affected and weaker political actors. At the very least, transparency and inclusiveness can help those who might be harmed by secretive practices to become knowledgeable critics: Rodger A. Payne and Nayef H. Samhat, Democratizing Global Politics: Discourse Norms, International Regimes, and Political Community (Albany: State University of New York Press, 2004 ): 59.

${ }^{30}$ Kratochwil argues that neither a utilitarian account focused on Hume's concept of self-interest, nor a contractualist model derived from Hobbes' theory of the sovereign provide adequate answers for the prescriptive force of certain rules. Instead, he contends that Durkheim's argument about the importance of emotional attachments created through ritual activity and communicative action offers a more promising approach to the subject: Friedrich V. Kratochwil, Rules,
} 
by fear of sanctions or force, not by voluntary compliance. Therefore, they are likely to collapse as soon as the threat of sanctions fades away. Obligations based on self-interest are better at facilitating voluntary compliance, but they are bound to disintegrate as soon as the structure of payoffs becomes negative. ${ }^{31}$ On the other hand, obligations based on moral principles, such as fairness, present an excellent potential to ensure firmer compliance, on a voluntary basis, mainly because of their ability to connect the individual and the social "selves" through emotional attachments. ${ }^{32}$ It is exactly this property that has enabled fairness to be effective at preserving social stability , increasing the rate of cooperation to public goods, or at enhancing social solidarity .

\section{2. Tractability and legitimacy}

As a general framework for solving moral disputes and addressing coordination problems, fairness represents a necessary, but not a sufficient dimension of legitimacy. A sound model of legitimacy needs also to be tractable, that is, its conception of fairness must be able to draw adherents at reasonable costs. The nature of the restrictions which actors agree to observe may vary significantly across time and space, as illustrated, for instance, by the changing standards for granting international recognition, that is, sovereignty, to the members of the international system . States are notoriously jealous of their sovereignty and hence, they are very suspicious of any attempt to weaken this mechanism of protection against external interference. However, this condition does not

Norms, and Decisions on the Conditions of Practical and Legal Reasoning in International Relations and Domestic Affairs (Cambridge: Cambridge University Press, 1989): 95-129.

${ }^{31}$ For a more detailed exposition of the relationship between coercion, self-interests and social compliance, see Hurd, "Legitimacy and Authority in International Politics": 383-87. For a more nuanced interpretation of the relationship between self-interest and social compliance, see Stephen Holmes, "The Secret History of Self-Interest," in Beyond SelfInterest, ed. Jane Mansbridge, J. (Chicago: 1990).

${ }^{32}$ For example, the demand for fairness on all sides, not the efficiency of the distributive outcome, has been demonstrated empirically to be the decisive factor for producing agreement in international negotiations: Harald Müller, "Arguing, Bargaining, and All That: Communicative Action, Rationalist Theory and the Logic of Appropriateness in International Relations," European Journal of International Relations 10, no. 3 (2004): 401. 
necessarily mean that a tractable notion of fair interventions must exclusively dwell on the modern principle of state sovereignty. Alternative conceptions are clearly available as illustrated by the ongoing cosmopolitan-communitarian debate, but the key factor that must be taken into account when comparing different conceptions of fairness is the degree to which they resonate with the normative beliefs and practices of the interpretative community involved in their definition and validation.

To begin with, the relationship between legitimacy and tractability cannot be separated from the cosmopolitan - communitarian debate about the character of sovereignty. As an ordering principle of international politics, sovereignty represents both a discourse on power and a form of political action. As a discourse on power, it tells us what power is within different historical episodes, how it should be interpreted, known and measured . As a form of political action, sovereignty is most effectively produced and reproduced through military interventions . Accordingly, as cosmopolitan approaches increasingly challenge the communitarian discourse on state power, one should then expect a gradual re-drawing of the boundary of moral obligations between the "inside" and “outside” of state authority. The specific contour of this boundary, and by extension the normative foundation of sovereignty, would be likely fixed through military interventions. In sum, any discussion regarding the tractability of the legitimacy of the use of force cannot ignore the implications of the communitarian-cosmopolitan debate for the reconfiguration of the principle of sovereignty, both as a power discourse and a form of political action.

For a communitarian, "the recognition of sovereignty is the only way of establishing an arena within which freedom can be fought and (sometimes) won”. For communitarians, sovereignty is an ethical requirement because only within states individuals can fulfill their potential for self-realization. The 
moral value of the state lies thus in its ability to maintain the institutional integrity of domestic spheres of justice that is, to protect "churches, universities, families and so on from tyrannical influence” . In short, it is crucial for individuals that their states are autonomous, recognized and treated as such by other autonomous states . Similar to cosmopolitanism, communitarianism enjoys a venerable tradition, inspired largely by Hegel's conception of the state , but its influence in international relations has been substantially larger. In fact, the structure of the current international system is to a great extent underpinned by the communitarian principle of the moral primacy of the state. The notion of state protection against external intervention is not only firmly stipulated in the UN Charter, but it also represents the core objective of any foreign policy.

On the other hand, for a cosmopolitan, the principle of sovereignty cannot be used by national leaders as a shield for committing political abuse against their fellow citizens. Individuals, not states, must be considered subject of justice in international relations. According to Charles Beitz, state autonomy lacks a coherent moral foundation if not for considerations of domestic social justice. Therefore, "interference with unjust institutions might be justified when it has a high probability of promoting domestic social justice . The principle of sovereignty must be thus reformulated in light of a reasonable "Law of Peoples" that will deny states unrestricted internal autonomy and traditional rights to war, except for self-defense and grave cases of human rights abuses . In sum, “only states whose institutions satisfy appropriate principles of justice can legitimately demand to be respected as autonomous sources of ends” . The cosmopolitan position enjoys a long-standing tradition in IR theory, ${ }^{33}$ going back to Kant’s essay on "Perpetual Peace” , but its view of sovereignty has gained more momentum in the recent past, especially after the end of the Cold War. The doctrine of “individual sovereignty”, and the concept of the "responsibility to protect” are two recent examples

${ }^{33}$ For an overview of the cosmopolitan and communitarian traditions of thought, see Chris Brown, International Relations Theory: New Normative Approaches (New York: Columbia University Press, 1992), Janna Thompson, Justice and World Order: A Philosophical Inquiry (London: Routledge, 1992). 
of initiatives promoted by the international community, underlying its growing commitment to adopt a more interventionist approach against gross human rights violations. ${ }^{34}$

The cosmopolitan - communitarian debate thus has an important implication for the relationship between legitimacy and tractability. It suggests that a tractable conception of legitimacy must include aspects that address not only the communitarian focus on state autonomy, but also the cosmopolitan interest in "duties beyond borders". The different conceptions of sovereignty advocated by the two approaches are both constitutive part of international practice, and hence a tractable model of legitimacy cannot be exclusively anchored in either a cosmopolitan or a communitarian standpoint. While the latter has been generally more influential in shaping the conduct of states, the former has gained significant ground in the recent past to the extent that military interventions have become very hard to legitimize in international affairs by invoking statecentered national interests alone. ${ }^{35}$ At the same time, cosmopolitan aspirations face bleak prospects of being rendered into concrete policies if they neglect to justify their position from a state perspective as well. ${ }^{36}$

\footnotetext{
34 The cosmopolitan offensive in international relations is also illustrated by the growing number of humanitarian interventions in the post Cold War period: Somalia (1993), Bosnia (1995), Kosovo (1999), Liberia (2002), Haiti (1993, 2004). The main bone of contention concerning this type of intervention revolves around the ethical, legal, and political conditions on the basis of which humanitarian interventions can be justified: Alex J. Bellamy, "Humanitarian Intervention and the Three Traditions," Global Society 17, no. 1 (2003), J. L. Holzgrefe, Humanitarian Intervention: Ethical, Legal, and Political Dilemmas (Cambridge: Cambridge University Press, 2003), Laura W. Reed, Carl Kaysen, and American Academy of Arts and Sciences. Committee on International Security Studies., Emerging Norms of Justified Intervention: A Collection of Essays from a Project of the American Academy of Arts and Sciences (Cambridge, Mass.: Committee on International Security Studies American Academy of Arts and Sciences, 1993), Nicholas J. Wheeler, Saving Strangers: Humanitarian Intervention in International Society (Oxford: Oxford University Press, 2000).

35 The "democracy-building" rationale offered by the Bush Administration in support of its intervention in Iraq illustrates, for instance, the necessity for transcending a strictly communitarian basis for international legitimacy.

${ }^{36}$ Despite its clear humanitarian rationale, the 1999 intervention in Kosovo could not have been conducted had the Western governments not justified it in terms resonant to their respective national interest Tony Blair, Prime Minister's Speech: Doctrine of the International Community at the Economic Club, Chicago (April 24, 1999); available from http://www.number-10.gov.uk/output/page1297.asp, Bill Clinton, Presidential Statement on Kosovo (White House, October 12, 1998); available from http://www.clintonpresidentialcenter.org/legacy/101298-presidential-statement-onkosovo.htm. On the other hand, by calling for measures permissive of humanitarian intervention, the recent proposals of the High Level Panel on Threats, Challenges, and Change United Nations, A More Secure World: Our Shared
} 
The concepts of fairness and tractability offer effective analytical tools for understanding why actors may be more inclined to follow certain constitutive arrangements of legitimacy and not others. The first concept probes the normative value of the rules, norms or principles informing the constitutive arrangements that characterize difference conceptions of legitimacy. The second concept tests their applicability to political practice by examining the degree to which they are informed by both cosmopolitan and communitarian models of sovereignty. Simply put, from second-order perspective a sound conception of legitimacy must be normatively tractable and substantively fair. A sound conception of legitimacy thus requires a form of reasoning that brings together a principled aspiration for fair justifications and a contextualist framework of application of cosmopolitan and communitarian inspiration. If fairness and tractability are the necessary building-blocks for bridging the normative-analytical gap from a second-order perspective, then what conception of legitimacy is best suited for bridging the same epistemological divide from a first-order perspective?

\subsection{Deliberative legitimacy}

From a first-order perspective, the concept of deliberative legitimacy offers the most appropriate constitutive framework properly discriminating between legitimate vs. illegitimate decisions to use force. I define the concept of deliberative legitimacy as the non-coerced commitment of an actor to

Responsibility (Dec 2004); available from http://www.un.org/secureworld/. and the UN Secretary General Kofi Annan, In Larger Freedom: Towards Development, Security and Human Rights for All - Report of the Secretary-General (March 21 2005); available from http://daccessdds.un.org/doc/UNDOC/GEN/N05/270/78/PDF/N0527078.pdf? OpenElement are indicative of an emerging consensus that sovereignty must involve a minimum of moral and legal responsibility of states to their fellow citizens as well as to the international community at large. 
abide a decision reached through a process of communicative action. Applied to the issue of the use of force, the conditions under which deliberative legitimacy can be validated are the following:

- The facts supporting decisions regarding the use of force are truthful and complete, as informed by the best evidence available.

- All affected parties must be allowed to participate in the argumentative discourse, and all participants should have equal rights to present an argument or to challenge a validity claim.

- $\quad$ Participating actors show genuine interest in using argumentative reasoning for reaching an understanding on the decision to use force.

The significance of the three validity claims of deliberative legitimacy stems from the unique way in which they address the issue of how to make sense of ambiguous or contradicting statements. Justifications for using force may often include deliberative ambiguities, which could be deliberate or unintentional. In the first case, ambiguities pertaining to arguments in favor or against the use of force are not necessarily caused by a lack of information, but by political attempts to distort or hide relevant evidence. The first condition of deliberative legitimacy takes care of this problem by investigating whether relevant existing information has been deliberately omitted or manipulated by interested parties. In the second case, ambiguities are the result of the fact that social reality is still unfolding and hence, hard evidence regarding the case under scrutiny is not yet available. This is why the second and third criteria of deliberative legitimacy are crucial for making sense of the various claims put forth by the actors involved. Unwillingness to include other relevant actors in the debate and refusal to engage in argumentative reasoning only serve to discredit claims made on that basis, because it clearly demonstrates the intent to pursue an ideological agenda, which is shaped by subjective considerations and hence, largely divorced from an intersubjectively-defined social reality. 
What this definition brings new in comparison to more conventional conceptions of legitimacy is a discourse ethics perspective. On one hand, it anchors the notion of legitimacy in the moral imperative of equal participation to deliberation of all actors affected by foreseeable consequences and side-effects of a particular decision. On the other hand, it insists that the rules governing the deliberative process must reflect the value-orientations of the actors involved. The linchpin holding these two elements together is communicative action. As a principle of justification, communicative action implies that equal dialogical participation and other-perspective taking (second and third validity criteria) are indispensable ingredients of a sound moral analysis. As a principle of application, communicative action is premised on the idea that truth, inclusiveness, and sincerity (first, second, and third validity criteria) represent a realistic common denominator for the valueorientations of the actors involved.

In other words, deliberative legitimacy is not only an analytical theory of social action explaining how actors coordinate their actions based on subjective interpretations of the legal or moral worthiness of a particular decision, but also a normative theory of justice underpinned by an emancipatory critique of power. From an analytical perspective, the key issue that deliberative legitimacy tries to clarify is whether the promoters of a military intervention try to reach a reasoned consensus on the legal justifications for the use of force, or they just engage in power games based on credible threats, promises, or rhetorical exchanges with no visible intention to achieve argumentative consensus with the other members of the international community on the definition of the situation and on the course of action. From a normative perspective, deliberative legitimacy represents the platform on the basis of which the moral points of contention between actors' justifications to use force can be ascertained and validated. Therefore, deliberative legitimacy 
validates the position of the party making systematic efforts to reach a reasoned consensus on the legal and moral justifications for using force. The legitimacy of an intervention is thus primarily contingent not upon the consensus reached by the parties involved, but on the manner in which this consensus, or lack of it, is attained. ${ }^{37}$

From a normative perspective, three scenarios could follow from this conclusion. First, if none of the three validity claims is met, then the legitimacy of the intervention is clearly absent, regardless of whether the majority of the actors involved eventually agree to authorize the use of force. Second, if participants are primarily oriented towards claims to truth and truthfulness (first and third condition) then a sufficient claim of legitimacy can be invoked in support of the respective intervention. This is so because actors express genuine concerns about the need to use force and they make systematic efforts to listen to the arguments of the others and to engage in argumentative reasoning. In other words, participants demonstrate a commitment to deliberative legitimacy, although the political context may prevent them from fully practicing it. Nevertheless, the fact that the deliberative context may be unduly influenced by strategic considerations represents a major weakness of the legitimacy of the intervention. Consequently, a strong claim of legitimacy can be invoked only when these two conditions are supplemented by a deliberative framework that is inclusive and allows participants to coordinate their actions plans based on the "best argument" available. In the latter case, participants demonstrably practice deliberative legitimacy for reaching the decision to use force.

\footnotetext{
${ }^{37}$ One could easily imagine a situation in which reasonable arguments are put forward by one of the parties, but strategic behavior of other actors prevents the attainment of an agreement on the use of force. The intervention could still be viewed as legitimate as long as its supporters make systematic efforts to engage into communicative action. The argument holds obviously true for the reverse situation when the opponents of an intervention are systematically engaged in communicative action, while the promoters refuse to negotiate their positions. Such an intervention would utterly lack deliberative legitimacy.
} 
From an analytical perspective, it is the use of speech acts that informs how actors coordinate their actions in the three scenarios described above. In the first case, perlocutionary speech acts represent the dominant mode of interaction between actors. ${ }^{38}$ Language is used strategically with the purpose of compelling the opponent to comply with goals that go beyond the manifest content of the speech act. In other words, actors' reasons to use force are defined independently of the deliberative context and they are pursued instrumentally through selective or misleading statements, exclusivist debates, and rhetorical posturing. In the second situation, actors predominantly rely on illocutionary speech acts in order to reach an understanding about the required conditions for the military intervention. As a result, actors' motivations for using force are largely, but not completely, shaped intersubjectively through deliberative intercourse based on considerations of truth and truthfulness. Strategic considerations remain nevertheless problematic, either because of domestic pressures or of a deficit of trust in the other side. The third scenario characterizes situations when actors use illocutionary speech acts for reaching not merely understanding, but also agreement on the conditions for using force. This implies that besides truth and truthfulness, actors demonstrate that the deliberative framework they use for exchanging arguments is inclusive and mutually respectful. Subjective preferences are being thus subdued by intersubjective, argumentatively-defined justifications for using force.

\footnotetext{
${ }^{38}$ According to Searle John R. Searle, Speech Acts: An Essay in the Philosophy of Language (London: Cambridge U.P., 1969), illocutionary and perlocutionary utterances are the most important categories of speech acts. The first refer to situations when actors express certain meanings by asserting, questioning, promising, or making requests. An illocutionary speech act occurs when an actor tries to make herself understandable to the others through a symbolic act: a remark, a comment, a command, an apology, a request etc. On the other hand, a perlocutionary action takes place when the person exposed to an illocutionary act undertakes a behavioral change: it gets scared, enthusiastic, bellicose, subdued, or gratified etc.
} 


\section{Conclusions: Bringing all together}

This article has taken issue with the epistemological position adopted by IR scholars on the issue of the legitimacy of the use of force. More specifically, it has argued that the study of legitimacy in either analytical or normative terms introduces important theoretical and practical limitations, by either divesting the concept of legitimacy of an important critical component or by undermining its applicability to the social realm. As a conceptual alternative, the article proposed a constitutive theory of legitimacy that reconciles the epistemological tension via the concepts of fairness and tractability and bridges the theoretical gap via the concept of deliberative legitimacy. The latter offers a moral-practical form of reasoning that brings together a universalistic aspiration for moral justification and a contextualist framework of practical application. As a principle of justification, deliberative legitimacy argues that decisions on the use of force must be the result of deliberative processes in which all actors potentially affected by foreseeable consequences and side-effects of that decision participate in the debate on an equal basis. As a principle of application, it insists that the rules governing the deliberative process must reflect the value-orientations of the actors involved, which must rely, at the very least, on premises of truth and sincerity.

In comparison to other conceptions of legitimacy, deliberative legitimacy addresses most successfully the issue of fairness in international relations. The reason for that is twofold. On one hand, deliberative legitimacy takes very seriously the principle of reciprocity of obligations among affected parties. On the other hand, it offers the most appropriate framework for assessing the nature of actors' consent to collective decisions to use force. The first reason is important because it underlies the ability of deliberative legitimacy to subject all parties to the same standards, regardless of their power status. The second reason effectively confronts another serious weakness of 
conventional forms of legitimacy by drawing a clear distinction between actors' constrained vs. voluntary consent for decisions to engage in military action. In short, a major theoretical contribution of deliberative legitimacy consists in leveling the political playing field among actors with respect to the influence they hold over decisions to use force. It achieves that by making sure that its validity criteria do not provide cover for undue privileges that some actors might unfairly use for swaying the group’s decision to apply military force.

Deliberative legitimacy also offers a balanced platform for addressing cosmopolitan and communitarian concerns on the use of force. First, it could help clarify those "grey zones" of ambiguity concerning the legal and moral standards for the use of force. Regardless of whether the issue is about, for instance, the legal basis of humanitarian interventions or the moral authority of regional organizations, deliberative legitimacy should be able to draw clear conclusions on the basis of the three validity claims. Second, it could help denounce and eventually prevent abuses by which communitarian or cosmopolitan justifications are sometimes offered as a disguise for objectives that lack solid legal or moral grounds. For example, the credibility of communitarian self-defense arguments or of just war standards of proportionality and reasonable success thus depends on the quality of the deliberative exchange between actors on these issues. Third, by adopting a pragmatic standpoint on the substance of the justifications for the use of force, deliberative legitimacy does, in fact, strike a fair balance between communitarian and cosmopolitan approaches to the use of force. The normative posture of the decision to use force will be thus contingent not upon rigid abstractions, but upon the persuasive quality of the cosmopolitan or communitarian arguments exchanged by actors during deliberations.

Besides the use of force, the research agenda on deliberative legitimacy could include applications 
in at least three important areas: global governance, regional integration, and foreign policy analysis. As the intensification of the globalization process is going to sharply increase the number of collective problems the international community will have to face, ${ }^{39}$ deliberative legitimacy could offer an insightful approach to understanding the causes of failure or success of multilateral negotiations, for example in areas of trade, environment or global justice. The degree to which the parties involved would agree to share truthful information, include all relevant actors in the debate and remain open to argumentative reasoning could overall constitute a good predictor for the success of the negotiation process. An important corollary of this research avenue is the relationship between deliberative legitimacy and the effectiveness of the implementation of multilateral agreements. The germane question in this case refers to the extent to which the legitimate outcomes of multilateral agreements might ultimately fail to yield the desired results due to a deficiency of deliberative legitimacy in the implementation phase. The application by the member states of the Kyoto Protocol to the United Nations Framework Convention on Climate Change represents, for instance, a good case study for testing this hypothesis.

Deliberative legitimacy could also benefit regional integration studies in two ways. On one hand, it can deepen our understanding of how integration occurs in a complementary way to traditional theories of regional integration. Unlike neo-functionalism ${ }^{40}$ or liberal-intergovernmentalism ${ }^{41}$ which emphasize utilitarian considerations exogenous to decision-making, a theoretical approach based on deliberative legitimacy would call attention to the normative factors involved in the process of argumentation around which integration revolves. Accordingly, regional integration may prove to be

${ }^{39}$ David Held and Anthony G. McGrew, Globalization/Anti-Globalization (Cambridge, UK: Polity, 2002), Joseph E. Stiglitz, Globalization and Its Discontents (New York: W.W. Norton, 2003).

${ }^{40}$ Ernst B. Haas, The Uniting of Europe; Political, Social, and Economical Forces, 1950-1957, The Library of World Affairs, No. 42 (London,: Stevens, 1958).

${ }^{41}$ Andrew Moravcsik, The Choice for Europe: Social Purpose and State Power from Messina to Maastricht, Cornell Studies in Political Economy (Ithaca, NY: Cornell University Press, 1998). 
the result not exclusively of spillover effects and rational two-level games, but also of successive attempts to improve the deliberative legitimacy of regional institutions, as illustrated, for instance, by the gradual extension of qualified majority voting in the European Union decision-making. On the other hand, deliberative legitimacy could provide a good theoretical angle for transcending the debate regarding the sui generis character of European integration. If the success of the latter is linked to the capacity of the European Union to consolidate the deliberative legitimacy of its institutions, then the possibility of replicating this process in other regions around the world might become more tangible.

Foreign policy analysis is another area in which deliberative legitimacy could make an important theoretical contribution, especially in relation to how crises are resolved within security communities. The stability and endurance of security communities has been generally attributed to the "thickness" of the identity shared by the members, which is assumed to bear a direct influence on their entertaining of dependable expectations of peaceful change. ${ }^{42}$ Internal crises may still occur but they are peacefully resolved by diplomatic means, although some of them might involve political showdowns based on representational force. ${ }^{43}$ Little is known, though, about the factors that steer the members of security communities to settling their differences by cooperative vs. confrontational means. The concept of deliberative legitimacy can partially fill this gap by showing how actors' disposition to embrace confrontational strategies of foreign policy (FP) is directly proportional to low levels of deliberative legitimacy. Conversely, the weaker the perceived deficiency of deliberative legitimacy, the more likely the actors will seek cooperative FP approaches for settling their disputes.

42 Emanuel Adler and Michael N. Barnett, Security Communities (Cambridge: Cambridge University Press, 1998).

${ }^{43}$ Janice Bially Mattern, Ordering International Politics: Identity, Crisis, and Representational Force (New York: Routledge, 2004). 
To conclude, deliberative legitimacy represents an epistemologically innovative, normatively relevant and theoretically coherent tool for the study of international politics. It advances an analytical framework that not only successfully addresses the epistemological tension between how legitimacy is construed and exercised, but it also brings together a normative aspiration for cosmopolitan and communitarian responsibilities and a contextualist framework of practical application. While this article examined the issue of the use of force as the main area of application of the concept, deliberative legitimacy is nevertheless pregnant with theoretical implications for a broader IR research agenda encompassing issues related to global governance, regional integration and foreign policy analysis. The ongoing debate regarding the United Nations (UN) reform would particularly benefit from taking deliberative legitimacy seriously. A carefully designed process of institutionalization of deliberative legitimacy could not only repair and reinforce global confidence in the UN, but it could also make it work more effectively in addressing the growing number of collective problems entailed by the globalization process. 